\title{
Pre-service Teachers' Learning Object Development: A Case Study in K-12 Setting
}

\author{
Yavuz Akpinar and Huseyin Simsek \\ Bogazici University, Istanbul, Turkey
}

\section{Akpinar@boun.edu.tr Huseyin.simsek@boun.edu.tr}

\begin{abstract}
Teachers use variety of media to support students' learning. Though there are many new tools and settlements in learning technologies and their specifications, there has been a fierce debate over learning objects and their development. This research aimed to examine the effect of preservice teachers' experience in information and communication technology (ICT) use on their learning object development through (1) inspecting type, number and organization of their learning object (LO) components authored in a non-commercial system, (2) evaluating quality of their learning objects using the Learning Object Review Instrument (Nesbitt \& Li, 2004), and (3) studying relationship between the components, quality and subject matter of their LOs. Seventysix pre-service teachers were asked to design and develop LOs in a non-commercial learning content development system. Analysis of their learning objects and a usability test data showed that the participants found the system easy to use in general. Novice and experienced information technology users were able to develop learning objects similar in size and features. The analysis showed meaningful correlation between the use of some of the learning object components. There seems to be significant relations between the quality of the LOs measured with the LORI items and some elements of the developed LOs, however, the novice and experienced groups' LOs did differ neither in overall ratings nor at nine individual items of the LORI. The study suggested some further work for developing quality LOs through collaborative learning resource authoring.
\end{abstract}

Keywords: Learning object, pre-service teachers, Learning object authoring, instructional assets, learning content management system

\section{Introduction}

Teachers play an important role in determining what and how students learn throughout their activities both in conventional and technology rich learning environments. Teachers are responsible for monitoring the flow of each student's activities, playing a meta-cognitive function for the students by probing their knowledge and reasoning, monitoring participation and student engage-

Material published as part of this publication, either on-line or in print, is copyrighted by the Informing Science Institute. Permission to make digital or paper copy of part or all of these works for personal or classroom use is granted without fee provided that the copies are not made or distributed for profit or commercial advantage AND that copies 1) bear this notice in full and 2) give the full citation on the first page. It is permissible to abstract these works so long as credit is given. To copy in all other cases or to republish or to post on a server or to redistribute to lists requires specific permission and payment of a fee. Contact Publisher@InformingScience.org to request redistribution permission. ment. Student activities must be rich and needs based so that teachers make their educational diagnosis and intervention accordingly. As student needs vary and those needs may be fulfilled with different task regimes, it would be functional for teachers to have access to a large activity pool which is constructed and enriched by teachers. E-learning systems replace the teacher to the center for learning, the teacher's role shifts from 
lecturer to that of course developer and, once a course is in session, the course facilitator (Cohen $\&$ Nycz, 2006). Because e-learning tools provide a means of easy communication and knowledge exchange platform, teachers can collaborate to construct and tailor the task based upon their students' performance records. A set of online tools and resources support teachers as they, in turn, support the students through active process. This set of online resources outline a suggested sequence of activities based on what has worked in the past; each activity listed is linked to additional information regarding the purpose of the given activity, an elaboration of what the activity entails, and tips for when to intervene. With the growth of Internet, particularly WWW, and the consequent increase in world wide connections, a new level of resource sharing has become possible (Vargo, Nesbit, Belfer \& Archambault, 2003). Online facilities for every level of education have developed new tools and concepts such as learning content management systems (LCMSs) and learning objects: A LCMS enables multiple users to easily share and re-use content, even if they are at different geographical location. For example, if someone has already created an image, everyone authorized can search for it in the repository and insert it into a lesson without being had to create it from scratch. This led to development of learning objects which is, according to the IEEE LTSC-LOMW Group (IEEE, 2005), an independent collection of content and media elements, hence it is a learning approach emphasizing interactivity, learning architecture and learning context (although some do free learning objects from context) and a metadata emphasizing storage methods and searchability (Barritt \& Alderman, 2004).

\section{Teacher Involvement in Learning Object Development}

While most of the research literature has focused on the specifications and possible designs of learning objects, the importance of the users has not gone unnoticed (Muirhed \& Haughey, 2005). Teacher involvement in the development of online learning resources has received support from researchers recently. As Lajoie (2003) highlighted, technology is only as good as the teachers who use it: It would be more accurate to note that teachers decide if and when and how learners access learning objects. Similarly, other researchers (Kay \& Knaack, 2005; Oliver, Harper, Hedberg, Wills \& Agostinho, 2002; Recker et al., 2005) have also pointed out the importance of including users in the development process. McNaught and her colleagues (McNaught, Burd, Whithear, Prescott \& Browning, 2003, p.12) concluded from a review of a research project that "Knowing about resources and having access to them are important, but knowing what to do with them in order to facilitate learning provides another set of complex challenges". From a constructivist perspective, instructors would form a community of practice who would develop a communal sense of the value of pedagogical attributes and be able to identify the aspects they considered essential to a quality learning object (Muirhed \& Haughey, 2005). These authors inspected variety of learning objects provided by the Le@rning Federation that showed many kind of "architectures" of learning objects that are emerging to address the specific needs of school children. The authors stated that learning objects do not have value or utility outside instructional contexts. Their value is in their application to classroom settings and to online environments where teachers may or may not be present. As a result, according to the authors, learning objects are designed to help teachers perform the following functions: (1) introduce new topics and skills, (2) provide reinforcement to existing skills, (3) extend learning by providing new means for presenting curricular material, (4) illustrate concepts that are less easily explained through traditional teaching methods, (5) support new types of learning opportunities not available in a classroom environment, and (6) provide enrichment activities for gifted and highly motivated students (p.26).

Recently, some researchers (Dunning et al., 2004; R. Jones, 2004; Haughey \& Muirhead, 2005; Major, Ainsworth \& Wood, 1997), have suggested that with the addition of simple templates, teachers will be able to make their own objects. Haughey and Muirhead (2005) stress that it is likely that teachers will be able to develop objects requiring activities such as "drag and drop," or "label the figure" or "put the items in a sequence". These activities engage learners and require 
more from them than taking notes on the topic. However, they are likely to engage the learner for less time and to a limited extent, compared to the possibilities provided by more complex learning objects. In the CELEBRATE project organised by European SchoolNet (2002-2004), many teachers made such objects for use in their classrooms. McCormick and his colleaques (McCormick, Scrimshaw, Li \& Clifford, 2004) found, however, that individually, many of the designed activities were to reinforce information, and a team model was most conducive to producing acceptable learning objects and such teams had a combination of content expertise, classroom instruction with ICT for this age group, and software programming expertise. They concluded that the development of learning objects would only be successful and sustainable if (1) sufficient teachers want to use LOs, (2) sufficient LOs are produced, (3) the ones produced are the ones that are wanted, and (4) the teachers are able to find and use the LOs they want successfully. (p. 157).

\section{Learning Object Development Platforms}

In developing learning objects, different type of information might be created using traditional tools such as spreadsheets, word processing, painting tools, HTML editors, gifmakers, video editors/capturers and some general and specific purpose software. In LO terms, picture, animation, simulation, sound file, hyperlink, game, video, downloadable-file are all called asset. Assets can be combined to form larger files, sharable content object (SCO). The number, quality and orientation of screen elements loaded into a lesson is an issue for development of LOs, though the LCMSs and authoring environments provide many facilities to create and edit screen components. The usage of those facilities should not require experience and expertise but should demand great care because research data for possible components of a computer based lesson suggests that for effective learning, screen design decisions should reflect balance among learner attributes, content factors, and processing requirements of the learning task (Hannafin \& Hooper, 1989). Well designed screens should visually stimulate, be easy to read, and exhibit no annoying or distracting features (Li, 2006). Commonly, it is suggested that no more than two or three types and sizes of fonts be used per screen (Stemler, 1997). However it has been suggested that only one font per screen be used unless certain material needs to be emphasized. In this case, varying the size and font of a text may attract attention (Garner, 1990; Shneiderman, 2000). Highlighting of text helps to control selective perception and focus attention on identified information (Hannafin \& Hooper, 1989). The use of graphics instead of text is also recommended when possible; Graphics may illustrate almost any fact, concept, or procedure (Sponder \& Hilgenfeld, 1994). Learning tends to be strongest when pictures supply redundant information, supplement information that is unclear or incomplete, or supply additional coding stimuli (M. G. Jones, 1995). Information presented in text is often better recalled and retained when supplemented with pictures (Hannafin \& Hooper, 1989). Authors should be cautious of using graphics for decoration, because graphics can become tiresome and/or interrupt the flow of the lesson (Barron, 1998; Hazen, 1985). Animated graphics is generally recognized that they can offer many subtle benefits (Rieber, 1994) for example highlighting key information, increasing student interest, and facilitating recall (Orr, Golas, \& Yao, 1994). Those authors also cite research data indicating that learners find it easier to complete lessons which use audio extensively to present information. Audio should be placed so that the learner can control the audio at any time and continue the lesson (Stemler, 1997). Further, the use of video is better for broader, abstract material, possibly with an emotional appeal. An abstract video segment may serve well as the medium for an advance organizer, and for a lesson summarization Taylor (1992). Finally, the use of color in lesson modules may be effective, but should be used sparingly, because the more color is used, the less effective it becomes (Stemler, 1997).

To ascertain to what degree a single media element, such as graphics, menus, audio, and video, contributes to the amount of learning that occurs is difficult, perhaps impossible: Generally, the most useful way to organize components of lesson modules is to organize the screen into func- 
tional areas (Grabinger, 1993). Designers should consistently decide where status and progress information, navigational buttons, content display control buttons, and illustrations will be located and use graphic devices such as shading, lines, and boxes to separate one area from another. The main recommendation is to keep the screen as simple and uncluttered as possible because presenting too much information at one time can be confusing and overwhelming (Orr et al., 1994; Overbaugh, 1994; Stemler, 1997). Simplicity is one of the most important goals of learning object design, development and implementation.

Regardless of the source, type and size of information and content, in standard LCMSs, authoring tools and web page editors, learning content and environment are statically connected. Hence for each topic, every subtopic has to be produced anew (Hitzke, Fjeld, Schluep \& Danuser, 2002). The task of authoring must be simple enough that a trained teacher without experience in computational skills would be able to use the system effectively (Major et al., 1997). Although relatively little research has been undertaken to assess the difficulties of these tasks for different groups of authors (e.g. experts and novices), what evidence suggests is that even experienced authors/teachers who are highly computer literate find these demands hard (Elliott, Jones \& Barker, 2002; Murray, Blessing \& Ainsworth, 2003). Recently, a study by Kay \& Knaack (2005) reported that pre-service teachers were good at forming story lines of learning objects, however, learning to program a learning object in complexities of Flash successfully was a tedious task for them. To achieve usability at the instructional level, the authoring system must offer instructional control which provides the author with the key decisions in a way that can easily be manipulated. It provides the critical dimensions of a strategy without offering so many instructional choices that the task becomes unreasonably complex.

Authoring systems have become popular because of their object-oriented visualization approaches for programming and courseware development. Further rich template repositories added practicality to authoring platforms. However, when used in a comprehensive manner, the distributed nature of control flow and hidden actions make it more difficult for novices to form a mental representation of an object-oriented program than of a corresponding procedural program (Milne \& Rowe, 2002). Similar findings were also reported in earlier research with program authors (Barr, Holden, Phillips \& Greening, 1999). Commercial companies provide, as they call, "zeroprogramming tools" that are aiming to solve some of the object-oriented programming difficulties. Boot and Van Rooij (1999) analyzed the process of instructional software development by novice developers such as domain specialists who used different authoring tools. The domain specialists were mostly former instructors with considerable experience in teaching and developing traditional instructional materials, but with limited multimedia and instructional software development experience. The research demonstrated that the development of instructional software was much harder for the domain specialists than expected, mainly because of authoring, technical and didactical problems. According to the researchers, although the users managed authoring tools, the production process still required considerable programming knowledge which is not generally possessed by many authoring system users. Further the authoring process still required insight in how to structure a program, how to deal with data variables, how to implement a navigation structure and how to apply an effective interaction design. Another finding was that the domain specialists' reuse of existing resources was impeded by the lack of technical knowledge of file formats, sizes, resolutions and interfacing, required to combine resources and programming structures. This problem is further densed by the fact that Internet technology, operating systems and authoring tools are constantly being changed and upgraded and also becoming increasingly more complex. Finally, it was found that even domain specialists with high instructional design experience had great difficulties to apply pedagogical models that made an optimal use of the new possibilities offered by multimedia systems and instructional software. 
Based on the assumption that in developing software, novices encounter many recurrent problem situations that require comparable solutions, and new object-oriented design patterns provide standard solutions to common software development problems. That is software templates, claimed to provide support on the authoring; the templates offer prestructured components of software and include different objects which may be higher level, empty lesson structures, default navigation methods, generic graphical user-interfaces and low level didactical objects (Boot, 2005; Varlamis \& Apostolakis, 2006). It has been suggested that (Bell, 1999; Boyle, 2003; Merriënboer \& Martens, 2002; Tripp \& Bichelmeyer, 1990) instructional software templates may positively affect the efficiency of the development process and compensate for the developers' lack of experience. This can be beneficial for the authoring of instructional software because more people with low instructional design and software production skills are becoming involved.

Although template based tools have the potential to overcome some software development problems, very little is known about their actual benefits in real life design projects. Recently Boot (2005) studied if and how instructional software templates provided by a commercial authoring environment, support domain specialists with low and high experience in producing instructional software. The study found that the novice and the experienced group did not significantly differ at the time spent on the development task and at the size of produced instructional software; the groups, however, differed significantly in the number of different types of question elements and the average number of information elements used in their software. The study concluded that the instructional software templates allowed too much freedom to the developers and lacked the needed amount of didactical support, and templates restricted the developers' creative freedom.

\section{Learning Object Development for and Use in K-12 Environments}

It has been pointed that learning object development and use in K-12 environments differ globally (Bennetta \& McGeeb, 2005). For example, Australia, Canada and New Zeland have made planned efforts to engage K-12 schools in the design and development of initiatives while in many other countries, learning objects have been an outcome of adoption by higher education. Additionally, the label of learning objects has not always been attached to repositories. In the UK, in 2003, the government announced a web portal called CurriculumOnline which is designed to give teachers easy online access to a wide range of digital learning materials which they can use to support their teaching across the curriculum. One year later, in Europe, the ARIADNE Foundation was created to exploit and further develop the results of the ARIADNE European Projects, which created tools and methodologies for producing, managing and reusing computer-based pedagogical elements and ICT supported training curricula. In the USA, Apple's Learning Exchange (http://ali.apple.com/) was one of the first repositories and yet the term 'learning object' was attached to the site recently. On the other hand, the National Science Foundation funded SMETE Digital Library (www.smete.org/smete/) was clearly developed as a learning object repository and is used as a resource and knowledge base by both $\mathrm{K}-12$ and higher education instructors (McGreal, 2004). Further, The notion of communities of practice can be traced back through the work of the MERLOT consortium in the USA which uses peer-reviews of learning objects as the basis for inclusion. Currently, the use of learning objects in K-12 is more instructor-driven through the use of LOs used within a traditionally learning framework, apparently different from what occurs in higher education (Bennetta \& McGeeb, 2005). In order to mature learning object projects, Porter, Curry, Muirhead and Galan (2002) in a review of learning object repositories for CANARIE, noted the importance of training and skill-development for teachers and the development of end-user applications as a further development in the use and the reuse of learning objects. 


\section{Problems of the Study}

The emergence of learning objects as a focus of educational interest is relatively new and much of the discussion has not been based on the actual development of objects. This research goes somewhat to address this issue in that the work has involved the analysis of actual objects. The usage patterns of authoring tools and content development system facilities and benefiting from development systems to prepare a set of e-learning content may depend on the system users' experience with information and communication technologies. Cognitive and usability issues become paramount to the effective learning object development. This study discusses pre-service teachers' development of learning objects in a LCMS and provides a quantitative measure and evaluation of impact of ICT experiences on different authors' use of assets, organization of assets and instructional directions in a learning object the authors create. In this regard, the study aimed to:

(1) examine pre-service teachers', both novice and experienced ICT users', development of learning objects with different (a) number of assets as picture, animation, simulation, sound file, hyperlink, game, video and downloadable-file, (b) text density on each learning objects as small amount, moderate amount and large amount, (c) number of instructional elements as advance organizers, questions and didactical directions, (d) number of screen orientations as sub-topics Sharable Content Object (SCO)-, templates, picture orientation, colors, main topics, font types and font sizes.

(2) test whether pre-service teachers find the selected LCMS easy to use in developing LOs.

(3) study relationship (a) between components of the developed LOs, (b) between the components and the type of subject matter of the developed LOs, (c) between the components and quality of the developed LOs.

(4) evaluate quality of the developed LOs using the Learning Object Review Instrument (LORI, version 1.5 by Nesbitt \& Li, 2004).

\section{Method}

\section{Subjects}

To investigate pre-service teachers' development of learning objects in a LCMS, a series of studies were conducted with 76 subjects ( 36 male and 40 female). The subjects were pre-service teachers, studying their final year in a school of education in order to be teachers of varying fields like Primary Education, English Language Education, Secondary School Science and Mathematics Education in 2006 spring semester. The subjects study their degrees in four or five years after a one-year English Language preparation. The ones who will teach in high schools study five years, but others study four years. Selection of the subjects was carried out on the basis of accessing pre-service teachers during the research activities. The participants contributed to the study on a voluntary basis. Before the study, they all studied at least two ICT related courses, "Introduction to Computing" and "Instructional Materials Development" courses, hence they were familiar to information and communication technologies. The subjects had experience in web based learning materials because some of their learning activities in Instructional Materials Development course were based on developing online support materials and web sites in a commercial web editor to teach a set of learning content.

\section{Materials: BU-LeCoMaS learning content management system}

The BU-LeCoMaS environment and the learning objects for K-12 developed by the subjects using the BU-LeCoMaS constituted materials of this study. The BU-LeCoMaS, learning content 
development and management system, is an easy-to-use LCMS requiring content authors with little or no technology expertise to develop learning objects. It helps online material developers with time, place and platform independent content authoring. The architecture of BU-LeCoMaS (Akpinar \& Simsek, 2006) can handle and execute any content inputted. It, then, helps to integrate textual content, sound, movie and animations to software packages, and enabling multimedia platform creation. It has lesson templates, layout templates and information creation and editing tools. Multiple users may easily and collaboratively construct, share and re-use content within the LCMS. Further it supports SCORM standards, allowing developed content to be used in different learning management systems based on the idea of reusable learning content as sharable content object. To create a small set of learning content, an authorized author can use the system as follows.

In the BU-LeCoMaS, learning materials may be sequenced and grouped to constitute a learning unit, size of which varies and depends on its author. In the root window of the system, an author may get a list of available learning units and learning topics. A learning topic is a subset of a learning unit. The BU-LeCoMaS supports both constructing a learning unit and constructing an asset, a granular learning content. The author specifies the title and description of the material she is creating, selects a template, object type, tree view type, background and foreground colors, selects style sheet; selects to create as template or to share it as "public template", and decides to include it in the subject index of the BU-LeCoMaS. The subject index of the BU-LeCoMaS may be used by the system to search the object repository of the BU-LeCoMaS, or by the authors to manage associations of their materials for learning units. Once the author enters relevant information and selects, for example, LO template Tutorial, the learning unit frame will be provided. The author will then receive a screen where the name of her materials appears with four sub-sections, namely Introduction, Advance Organizer, Read\&Study and Images. The author may select any sections and designs (see Figure 1).

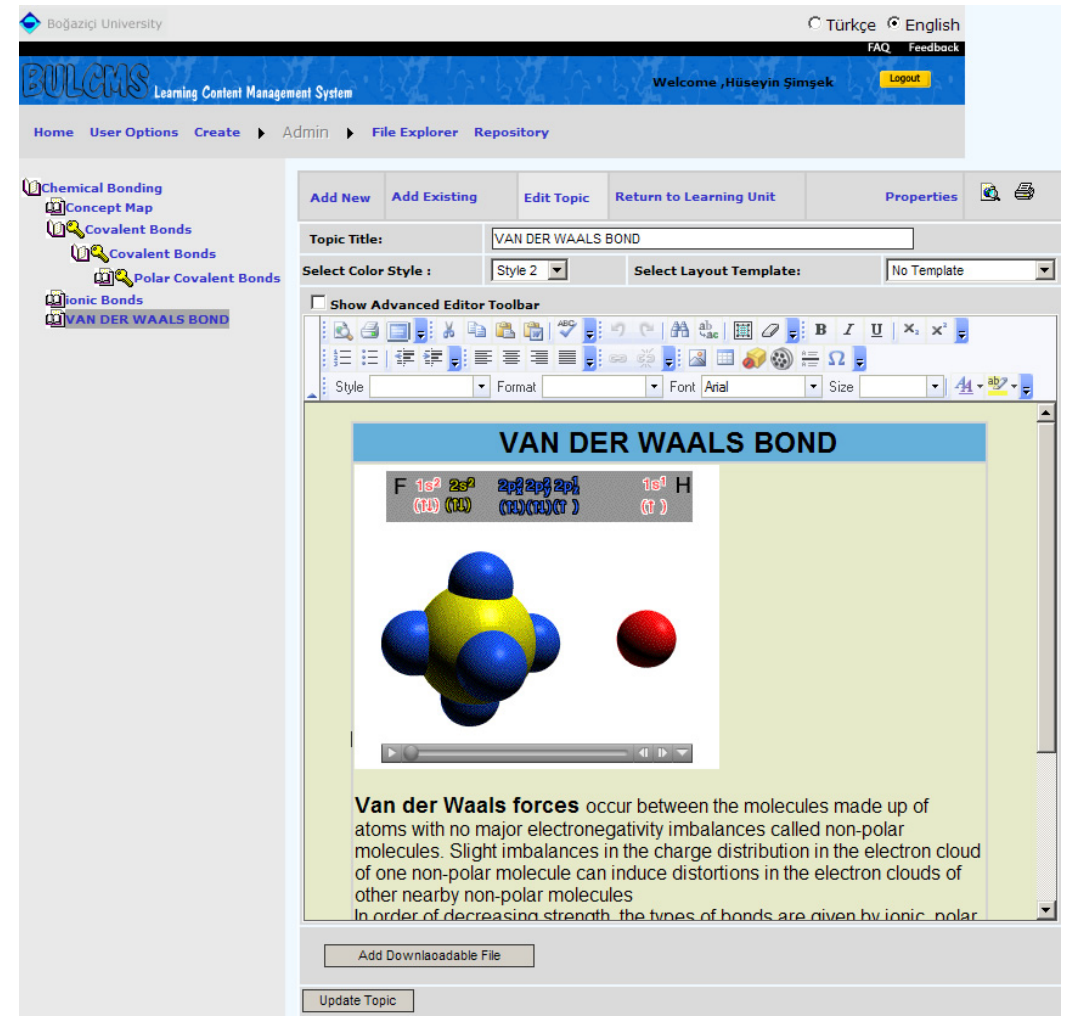

Figure 1: A screenshot from BU-LeCoMaS: Editing object 
The object order in the system is very hierarchical, once a LO template is used, the author may modify the order of the learning topics or assets, digital elements of the unit. For example; in the template, LO template Tutorial, the author is given four sections; the author may wish to re-order the sections and may want "Images" section to appear before "Advance Organizer" section. The author may also use the editing palette to design and modify screen layout of each learning topic or asset. The edit palette contains facilities to edit text, picture, table, web page, hypertext and external file management including file insertion. Once the set of learning material is organized by the author(s), the author may wish to scormify and pack it. The BU-LeCoMaS handles these tasks as follows: (1) There are two facets of the implementation of the SCORM standard in a LCMS. One is the human side, the second is the machine (technical) side. Since the target group that will use the BU-LeCoMaS is neither computer engineers nor e-learning specialist [instructional designers] but teachers and lecturers, users' effort have to be minimal in both of these phases. SCORM uses some jargon like asset, sco, and learning object for the components of the e-learning content. In the BU-LeCoMaS, in user interface part, these labels were converted into ones that are more understandable such as files, learning topics and learning units. Content organization of the learning object is provided manifests and sub-manifests in SCORM. In the BULeCoMaS, a tree view architecture is used to create and manage the content organization of the learning units. In order to provide a usable interface for the LCMS, some advanced SCORM tags are hidden under the "advanced" button. (2) In technical part, all tasks necessary to make a SCORM compliant content package may be accomplished by selecting "SCORM compliant" checkbox in the export menu. The system creates necessary SCOs as html files, and copies these SCOs and dependent files (images, multimedia and other files) into the same folder. In SCO files, necessary SCORM functions (LMSIntiliaze, LMSFinish and other custom functions) are written by the BU-LeCoMaS. Then, imsmanifest.xml file which holds all information about content organization and metadata is created according to the learning unit database information and saved in the same folder with the SCOs. Lastly, JavaScript functions responsible for finding SCORM API and running other SCORM functions are created and saved automatically. The content package components are bound in the form of a compressed archive file which is named the Package Interchange File (PIF). SCORM recommends that content packages be created as PIFs in the format of PKZip v2.04g (.zip) that is conformant to RFC1951 (SCORM, 2004). Thus, the LCMS compresses all content packages into a zip file and presents to the author. The BULeCoMaS in this work has been implemented through software tools including MS Visual Studio.NET (ASP.NET, C\#.NET) Macromedia MX, XML and SQL Server.

\section{Procedure and Data}

When the subjects agreed to participate in the study, they were first provided with a username and a password to the BU-LeCoMaS server and taken to a one-hour training about use of the BULeCoMaS learning content management system. The training was carried out in four sessions as the number of subjects exceeded the number of PCs in the computer lab where they also take some of their information technology courses. The lab was equipped with one server and $20 \mathrm{PCs}$ organised in U shape in the room, all connected to the net. In their ICT in Education course, the subjects were asked to use the system facilities and develop a set of web based materials (as learning objects) for a part of their chosen learning unit. The subjects were instructed to develop learning objects covering materials to be studied within 10-20 minutes. They were instructed to use any sort of learning materials from text to animations and from static graphics to video segments. They were allowed to re-use graphics borrowed from Internet: they were free to use anything they found appropriate for their instruction. During their usage of the system, one of the researchers was present in the lab for possible technical problems but did not intervene in the participants' work. The participants developed 76 learning objects among which 26 LOs were in sci- 
ence, 13 LOs were in mathematics, 21 LOs were in social science, and 16 LOs were in language learning units.

Following the participants' development of learning objects for K-12 in a four hours (in two consecutive days) work with the BU-LeCoMaS, they were then given a usability questionnaire with 44 five-point Likert type items and two essay items (five additional questions collected personal information) in order to measure the usability of the content development system, BU-LeCoMaS. The scale was previously developed and used in testing usability of a similar tool (Akpinar, 2002), and had reliability evidence: Cronbach's alpha reliability coefficient of the questionnaire was estimated in this study as .93 . The participants' responses to the usability questionnaire was converted into numerical values as their responses on the scale of each statement: Strongly disagree: 1, Disagree: 2, Neutral: 3, Agree: 4, Strongly agree: 5. Then each participants' total usability score was estimated. Those scores showed a normal distribution and the mean of those scores is 173.03 out of a highest possible score of 220.00.

The developed learning objects were then closely examined by two researchers who analyzed the 76 LOs and counted elements of the designed learning objects in terms of (1) number of assets (picture, animation, simulation, sound file, hyperlink, game, video, downloadable-file), (2) text density (small amount, moderate amount and large amount of text) on each learning object, (3) number of instructional elements (advance organizers, questions and didactical directions) and (4) number of screen orientations (sub-topics -Sharable Content Object (SCO)-, templates, picture orientation, , colors, main topics, font types and font sizes). SPSS estimated Shapiro-Wilk coefficients on the data sets showed that the data was distributed normally.

Table 1: Comparing novice and experienced ICT users' elements of LOs

\begin{tabular}{lccccccc}
\hline & \multicolumn{2}{c}{ Novice } & & \multicolumn{2}{c}{ Experienced } & & \\
\cline { 2 - 3 } \cline { 6 - 7 } & Mean & SD & & Mean & SD & t & p \\
\hline Usability test score & 170.14 & 21.74 & & 174.13 & 20.57 & -.74 & .46 \\
Text density & 1.95 & .50 & & 2.07 & .63 & -.78 & .44 \\
\# of Inst. elements & 4.14 & 6.05 & & 4.98 & 5.76 & -.56 & .58 \\
\# of SCOs & 3.10 & 3.77 & & 2.78 & 2.75 & .40 & .69 \\
\# of Templates & 3.14 & 1.42 & & 3.07 & 1.45 & .19 & .85 \\
\# of Picture orientation & 3.29 & 2.94 & & 3.11 & 2.22 & .28 & .79 \\
\# of Font type/sizes & 6.43 & 2.25 & & 6.33 & 2.24 & .18 & .86 \\
\# of Topics & 7.24 & 3.62 & & 6.89 & 3.14 & .41 & .68 \\
\# of Colours & 2.10 & .99 & & 2.67 & 2.14 & -1.19 & .24 \\
\# of Main topics & 4.14 & 1.82 & 4.11 & 1.71 & .078 & .94 \\
\# of Assets & 12.57 & 20.61 & 14.33 & 29.98 & -.25 & .81 \\
\hline * P<.05; df=74; Novice: $\mathrm{n}=21 ;$ Experienced: $\mathrm{n}=55$ & & & &
\end{tabular}

The participants who self-perceived himself/herself as novice (21 participants) and the ones perceived experienced (55 participants) ICT user were compared on the basis of usability scores on the system and elements of their LOs. The $t$ test carried out on the participants' usability data (Table 1) showed that $(\mathrm{t}=-.74 ; \mathrm{p}>.05)$ there is not a meaningful difference between the novice users' and the experienced users' total usability scores on the system. The result indicates that the 
participants' average perception of the BU-LeCoMaS facilities was positive (mean of those scores is 173.03 out of 220.00) in general: The current state of the most facilities was confirmed. However, there is a need for small amendments in the BU-LeCoMaS to satisfy users. Further $t$ tests (equality of variances was checked) showed that the pre-service teachers grouped as self perceived novice and experienced ICT users did not significantly $(\mathrm{p}>.05)$ differ in using assets, instructional elements, amount of text and number of screen orientations in developing their learning objects. Whether all these variables are correlated with each other and with usability scores, a series of correlation studies were also undertaken (Table 2).

Table 2: Correlation matrix between components of the designed learning objects

\begin{tabular}{|c|c|c|c|c|c|c|c|c|c|c|}
\hline & 1 & 2 & 3 & 4 & 5 & 6 & 7 & 8 & 9 & 10 \\
\hline \multicolumn{11}{|c|}{ Learning Objects $(n=76)$} \\
\hline 1. \# of Assets & - & .04 & -.03 & .02 & $.25^{*}$ & .09 & .03 & .04 & .11 & .17 \\
\hline 2.\# of Inst. Elements & & - & $.41 * *$ & .14 & .06 & $.25^{*}$ & $.52 * *$ & -.04 & $.26^{*}$ & .18 \\
\hline 3. \# of SCO & & & - & .10 & .11 & .16 & $.85 * *$ & -.02 & -.16 & .08 \\
\hline 4. \# of Template & & & & - & $.33 * *$ & $.29 *$ & .20 & .03 & .19 & -.04 \\
\hline 5. \# of Picture Or. & & & & & - & .18 & .18 & .03 & .15 & -.15 \\
\hline 6. \# of Font Formats & & & & & & - & $.34 * *$ & $.43 * *$ & $.36 * *$ & .04 \\
\hline 7. \# of Topics & & & & & & & - & -.01 & $.39 * *$ & .14 \\
\hline 8. \# of Color & & & & & & & & - & .01 & .01 \\
\hline 9. \# of Main topics & & & & & & & & & - & .12 \\
\hline 10. Text Density & & & & & & & & & & - \\
\hline
\end{tabular}

The analysis revealed that usability test scores and the used amount of text in LOs did not meaningfully correlate with any of the other elements, but meaningful correlations was found between: (1) the number of instructional elements and number of $\mathrm{SCO}$, number of font formattings, number of topics and number of main topics; (2) number of picture orientation and number of assets and number of templates; (3) number of font formattings and number of instructional elements, number of templates; (4) number of topics and number of instructional elements, number of SCO, number of font formattings, and number of main topics.

In order to test whether uses of assets, instructional elements, amount of text and material organization in the designed LOs differ, the participants' learning objects were grouped in terms of content fields as science, mathematics, social sciences and language. The four groups of learning objects were then compared on the basis of their assets, instructional elements, amount of text and material organization in the screen orientation. ANOVA tests (Table 3 ) demonstrated that the participants' use of assets, instructional elements, and material organization in the screen orientation at four types of content areas did not significantly differ, the only significant difference was observed at the amount of text, the post hoc tests on four groups' data (Table 4) showed that learning objects for social science contents had significantly $(p<.05)$ more text than learning objects for language contents, but other post hoc comparisons did not show remarkable differences. 
Table 3: ANOVA test for components of the designed learning objects

\begin{tabular}{|c|c|c|c|c|c|c|}
\hline & & Sum of Squares & $\mathrm{df}$ & Mean Square & $\mathrm{F}$ & $\mathrm{p}$ \\
\hline \multirow{2}{*}{ \# of SCO } & Between Groups & 13.27 & 3 & 4.42 & \multirow{2}{*}{.47} & \multirow{2}{*}{.71} \\
\hline & Within Groups & 681.42 & 72 & 9.46 & & \\
\hline \multirow{2}{*}{ \# of Template } & Between Groups & 8.20 & 3 & 2.73 & \multirow{2}{*}{1.35} & \multirow{2}{*}{.27} \\
\hline & Within Groups & 146.16 & 72 & 2.03 & & \\
\hline \multirow{2}{*}{$\begin{array}{l}\text { \# of Picture Orienta- } \\
\text { tion }\end{array}$} & Between Groups & 10.49 & 3 & 3.50 & \multirow{2}{*}{.59} & \multirow{2}{*}{.62} \\
\hline & Within Groups & 427.62 & 72 & 5.94 & & \\
\hline \multirow{2}{*}{ \# of Font Formats } & Between Groups & 29.44 & 3 & 9.82 & \multirow{2}{*}{2.07} & \multirow{2}{*}{.11} \\
\hline & Within Groups & 341.97 & 72 & 4.75 & & \\
\hline \multirow{2}{*}{ \# of Topics } & Between Groups & 18.09 & 3 & 6.03 & \multirow{2}{*}{.56} & \multirow{2}{*}{.64} \\
\hline & Within Groups & 776.90 & 72 & 10.79 & & \\
\hline \multirow{2}{*}{ \# of Color } & Between Groups & 3.77 & 3 & 1.6 & \multirow{2}{*}{.34} & \multirow{2}{*}{.80} \\
\hline & Within Groups & 267.21 & 72 & 3.71 & & \\
\hline \multirow{2}{*}{ \# of Main topics } & Between Groups & 1.50 & 3 & .50 & \multirow{2}{*}{.16} & \multirow{2}{*}{.92} \\
\hline & Within Groups & 222.43 & 72 & 3.09 & & \\
\hline \multirow{2}{*}{$\begin{array}{l}\text { \# of Instructional } \\
\text { Elements }\end{array}$} & Between Groups & 47.79 & 3 & 15.93 & \multirow{2}{*}{.46} & \multirow{2}{*}{.71} \\
\hline & Within Groups & 2482.46 & 72 & 34.48 & & \\
\hline \multirow{2}{*}{ \# of Assets } & Between Groups & 1098.94 & 3 & 366.32 & \multirow{2}{*}{.47} & \multirow{2}{*}{.70} \\
\hline & Within Groups & 55985.16 & 72 & 777.57 & & \\
\hline \multirow{2}{*}{ Text Density } & Between Groups & 3.12 & 3 & 1.04 & \multirow{2}{*}{3.16} & \multirow{2}{*}{$.03 *$} \\
\hline & Within Groups & 23.76 & 72 & .33 & & \\
\hline
\end{tabular}

$* \mathrm{p}<.05$

Table 4: Post Hoc Tests (Tukey HSD)

\begin{tabular}{lcccc}
\hline & $\mathrm{n}$ & Mean & SD & $\mathrm{p}$ \\
\hline Text Density in Social Sciences LOs & 21 & 2.33 & 0.48 & $.04 *$ \\
Text Density in Language LOs & 16 & 1.81 & 0.65 & \\
\hline$* \mathrm{p}<.05$ & & & &
\end{tabular}

\section{Evaluation of the Developed Learning Objects}

To establish a learning object repository for various level requires criteria to assist teachers develop, submit and assess LOs. These criterias are crucial means of quality assurance (Friesen, 2005; Krauss \& Ally, 2005) that supports the communication of meaningful feedback to designers for product improvement. For that purpose, Nesbit and Li (2004) developed a Learning Object Review Instrument (LORI 1.5) that this study employed because its developers provided evidence that LORI can be used to reliably assess some aspects of LOs. LORI 1.5 uses 9 items with brief descriptive rubrics associated to each item and Likert-style five point response scale and the items are scored from low (1) to high (5). If an item is judged not relevant to the LO, or if the reviewer does not feeel qualified to judge that criterion, then the reviewer may opt out of the item by selecting "not applicable". The items of LORI 1.5 is given in the first column of Table 5. In order to evaluate the LOs developed by the subjects, pre-service teachers, four professional instructional 
designers were asked to review and rate the LOs individually using LORI scoring sheets. Each instructional designers reviewed $38 \mathrm{LOs}$, hence each LO was reviewed by two reviewers. Following the reviewing and rating process of $76 \mathrm{LOs}$, the researchers combined the ratings and estimated average ratings of each LO. Average ratings were estimated both for each of nine issue for a particular LO and for overall rating of that LO. The reviewers' overall ratings for a LO was obtained through summing up points given to each nine issue for a particular LO. A formative reliability analysis of the LORI 1.5 with the pre-servicers' data revealed that overall internalconsistency reliability (Cronbach's alpha) of the LORI 1.5 is .87.

Table 5: LORI scores of the developed learning objects

\begin{tabular}{|c|c|c|c|c|c|c|}
\hline \multirow[b]{2}{*}{ LORI items } & \multicolumn{2}{|c|}{ Reviewer 1} & \multicolumn{2}{|c|}{ Reviewer 2} & \multicolumn{2}{|c|}{ Two Reviewers } \\
\hline & Mean & SD & Mean & SD & Mean & SD \\
\hline $\begin{array}{l}\text { 1. Content Quality: Veracity, accuracy, balanced presenta- } \\
\text { tion of ideas, and appropriate level of detail }\end{array}$ & 3.26 & 1.35 & 2.68 & .99 & 2.97 & .99 \\
\hline $\begin{array}{l}\text { 2. Learning Goal Alignment: Alignment among learning } \\
\text { goals, activities, assessments, and learner characteristics }\end{array}$ & 2.61 & 1.36 & 2.61 & .93 & 2.61 & .90 \\
\hline $\begin{array}{l}\text { 3. Feedback and Adaptation: Adaptive content or feedback } \\
\text { driven by differential learner input or learner modeling }\end{array}$ & 2.14 & .98 & 1.46 & .75 & 1.80 & .66 \\
\hline $\begin{array}{l}\text { 4. Motivation: Ability to motivate and interest an identified } \\
\text { population of learners }\end{array}$ & 3.01 & 1.32 & 2.40 & .99 & 2.71 & .92 \\
\hline $\begin{array}{l}\text { 5. Presentation Design: Design of visual and auditory infor- } \\
\text { mation for enhanced learning and efficient mental processing }\end{array}$ & 3.27 & 1.28 & 2.18 & 1.11 & 2.73 & .94 \\
\hline $\begin{array}{l}\text { 6. Interaction Usability: Ease of navigation, predictability of } \\
\text { the user interface, and quality of the interface help features }\end{array}$ & 3.26 & 1.43 & 2.88 & .69 & 3.07 & .81 \\
\hline $\begin{array}{l}\text { 7. Accessibility: Design of controls and presentation formats } \\
\text { to accommodate disabled and mobile learners }\end{array}$ & 3.82 & 1.11 & 2.17 & .95 & 3.00 & .71 \\
\hline $\begin{array}{l}\text { 8. Reusability: Ability to use in varying learning contexts } \\
\text { and with learners from differing backgrounds }\end{array}$ & 3.38 & 1.08 & 2.28 & .93 & 2.83 & .80 \\
\hline $\begin{array}{l}\text { 9. Standards Compliance: Adherence to international stan- } \\
\text { dards and specifications }\end{array}$ & 5.00 & 0.00 & 5.00 & 0.00 & 5.00 & 0.00 \\
\hline Mean & 3.30 & 1.10 & 2.63 & 0.82 & 2.97 & 0.75 \\
\hline
\end{tabular}

The quantitative analysis of the LORI scoring sheets show that learning objects developed by the pre-servicers are moderately rated by the reviewers. Overall, only the standards compliance item for the learning objects is rated perfect. The feedback and adaptation item for the LOs is received the lowest scores. In terms of content quality, among 76 LOs, there are high quality LOs $(40 \%$ of the LOs are rated as high or close to high) with accurate and well-presented content. However, the content is not entirely free of error in some of the LOs and some students may be misled in. In those LOs, arguments are not clearly supported by ideas, or presentations do not sufficiently emphasize key points and significant ideas with an appropriate level of detail. Item 2 measured whether each LO contained lesson objectives, activities to accomplish those objectives and included assessment tools. The first and second reviewer rated $18 \%$ and $25 \%$ of the total LOs, respectively, as closely high or high quality in terms of learning goal alignment. Some learning goals in some of the LOs are not appropriate for the intended learners. Some of the learning objects are insufficient to enable learners to accomplish the learning goals. The learning activities, content and assessments provided by the object do not align with the declared goals in some of the LOs. In addition, many of the participants' LOs received low ratings from both reviewers; 
first and second reviewer's rating are $85 \%$ and $90 \%$ of the total LOs, respectively, as from low to moderate quality in terms of adaptivity of content to learner needs that the item 3 measured. Many of the LOs are unable to tailor instructional activities to the specific needs of the learners. A model of the learner is not maintained in those LOs that influence the behavior of the learning object. The LOs mainly present content, but not use learner responses to adapt subsequent presentations and deliver rich feedback. In some of those LOs, interactivity for navigation or selection of information is supported but the delivered feedback is poor.

The item 4 checked the ability to motivate and interest an identified population of learners of the LOs. In many of LOs there are challenges embedded in the learning activities, but the learner control was only on hyperlinks. Some LOs failed to relate content to the students' knowledge and real-life experiences. Level of activities did not widely ranged and attractive features needed to be improved. Despite their motivational shortcomings, the objects may still be helpful to learners, but have to be revised. On the item 5, the LOs received similar ratings; In terms of presentation design, some of the LOs use animations and graphics very intensively but fail to support those graphical representation with brief textual content. However, the textual content in some of the other LOs are too much for the learners to read on the screen; Audio and video are sometimes used for variety but not always for enhancing learning of the content; The choice of images, colors or sounds interferes with the learning goals; The use of font formats are not consistent throughout a series of screens and overuse of color is generally observed. Decorative features are, generally, aesthetically pleasing, but some of them interfere with learning goals. Overall, the LOs are rated as moderately designed. The item 6 looks into the user interface design features at which the LOs are rated as average quality. The problematic issues on some of the LOs are that there are not always instructions guiding the use of the interface; Navigation through the object is easy, but the behavior of the user interface is not consistent and predictable in some of the LOs, also static images or text are generally used more than interactive features in the LOs. Seldom hyperlinks or buttons are not functioning.

The pre-servicers developed LOs which may be accessed over the net, but most learning objects consisting of an HTML page with an embedded animation, but do not provide captions for auditory narration and have supplementary auditory description of the visual actions, hence hearing and visually impaired learners are not considered. Overall accesibility rating for the LOs is average. Reusability principles are also moderately fulfilled in general. Small number of LOs has glossaries and summaries of prerequisite concepts. Many of the LOs avoid references to other components of the course. Most of the LOs can only be used by only the target group of students, however with some modifications they could be adapted to other level of students and may be to other contents. Lastly, all of the learning objects adhere to relevant standards and specifications including IEEE, SCORM and W3C. Metadata tags are provided in a code file and packed within the zip file of the objects.

In summary, the LOs are all in "tutorial" mode and mostly sequenced a few SCOs to form a LO. The contents are mostly presented in a didactic manner and student-centered activities are not common in the LOs.

In this part of the study, the pre-service teachers were grouped as the self-perceived novice and experienced ICT users. Their LOs were compared through $t$ tests on the basis of reviewers' rating through LORI 1.5 (Table 6). The groups' LOs did differ neither in overall ratings nor at nine individual items of LORI 1.5 . 
Pre-service Teachers' Learning Object Development

Table 6: Comparing LORI scores of novice and experienced ICT users' learning objects

\begin{tabular}{|c|c|c|c|c|c|c|}
\hline \multirow[b]{2}{*}{ LORI items } & \multicolumn{2}{|c|}{ Novice } & \multicolumn{2}{|c|}{ Experienced } & \multirow[b]{2}{*}{$\mathrm{t}$} & \multirow[b]{2}{*}{$\mathrm{p}$} \\
\hline & Mean & SD & Mean & SD & & \\
\hline Content Quality & 2.82 & .82 & 2.99 & 1.053 & -.65 & .52 \\
\hline Learning Goal Alignment & 2.76 & .98 & 2.55 & .88 & .87 & .39 \\
\hline Feedback and Adaptation & 1.68 & .62 & 1.85 & .72 & -.87 & .39 \\
\hline Motivation & 2.53 & .94 & 2.74 & .93 & -.83 & .41 \\
\hline Presentation Design & 2.61 & .91 & 2.80 & .92 & -.77 & .45 \\
\hline Interaction Usability & 3.16 & .91 & 2.99 & .76 & .77 & .44 \\
\hline Accessibility & 3.16 & .73 & 2.93 & .71 & 1.19 & .24 \\
\hline Reusability & 2.90 & .70 & 2.87 & .84 & .13 & .90 \\
\hline Standards Compliance & 5.00 & .00 & 5.00 & .00 & & \\
\hline Total & 26.61 & 4.47 & 26.70 & 5.27 & -.07 & .94 \\
\hline
\end{tabular}

$* \mathrm{p}<.05 ; \mathrm{df}=74 ;$ Novice: $\mathrm{n}=21 ;$ Experienced: $\mathrm{n}=55$

A series of correlation tests are also conducted between ratings of LORI items and number of LO elements in order to examine the dependency of a LO quality measured by LORI items to the LO elements (Table 7). Number of assets and number of colors used in the developed LOs and usability scores of LO developers did not correlate with any of the LORI items. Though not pretty high, there seems to be meaningful relations between the LORI items and the developed LO elements. The significant relationship between presentation design and number of templates in the LOs is. $26(\mathrm{p}<.05)$ as minimum, and between content quality and number of topics is $.57(\mathrm{p}<.01)$ as maximum. The LORI items have noteworthy relations with some of the LO elements as follows:

- Content Quality has meaningful relations with the number of (1) SCOs, (2) instructional elements, (3) templates, (4) font formats, (5) topics, (6) main topics and (7) text density.

- Learning Goal Alignment has meaningful relations with the number of (1) SCOs, (2) templates, (3) font formats, (4) topics and (5) main topics.

- Feedback and Adaptation has meaningful relations with the number of (1) instructional elements, (2) font formats and (3) main topics.

- Motivation has meaningful relations with the number of (1) instructional elements, (2) templates, (3) font formats, (4) topics and (5) main topics.

- Presentation Design has meaningful relations with the number of (1) instructional elements, (2) templates, (3) font formats, (4) topics and (5) main topics.

- Accessibility has meaningful relations with the number of main topics.

- Reusability has meaningful relations with the number of (1) picture orientation and (2) main topics.

- Standards Compliance has meaningful relations with the number of (1) SCOs, (2) instructional elements, (3) templates, (4) font formats, (5) topics and (6) main topics. 
Table 7: Correlations between scores of LORI items and number of LO elements

\begin{tabular}{|c|c|c|c|c|c|c|c|c|c|}
\hline & \multicolumn{9}{|c|}{ LORI Items } \\
\hline & 1 & 2 & 3 & 4 & 5 & 6 & 7 & 8 & Total \\
\hline & \multicolumn{9}{|c|}{ Learning Objects $(n=76)$} \\
\hline \# of Assets & .22 & .23 & .20 & .17 & .22 & -.08 & .17 & .21 & .23 \\
\hline \# of SCO & $.30 *$ & $.27^{*}$ & .10 & .15 & .23 & $.32 * *$ & .03 & .04 & $.27 *$ \\
\hline \# of Inst. Elements & $.39 * *$ & $.40 * *$ & $.41 * *$ & $.45^{* *}$ & $.33^{* *}$ & $.40 * *$ & .23 & .17 & $.47 * *$ \\
\hline \# of Template & $.27 *$ & $.41 * *$ & .24 & $.32 * *$ & $.26^{*}$ & $.30 *$ & .08 & .11 & $.34 * *$ \\
\hline \# of Picture Or. & .13 & .21 & .09 & .22 & .18 & -.11 & .20 & $.30 *$ & .21 \\
\hline \# of Font Formats & $.41^{* *}$ & $.39 * *$ & $.38 * *$ & $.43 * *$ & $.26^{*}$ & $.46^{* *}$ & .13 & .08 & $.44 * *$ \\
\hline \# of Topics & $.57 * *$ & $.41 * *$ & .24 & $.41^{* *}$ & $.36^{* *}$ & $.50 * *$ & .20 & .19 & $.50 * *$ \\
\hline \# of Main topics & $.55^{* *}$ & $.29 *$ & $.27^{*}$ & $.40^{* *}$ & $.29 *$ & $.38 * *$ & $.33^{* *}$ & $.30 *$ & $.48^{* *}$ \\
\hline Text Density & $.31 *$ & -.16 & .16 & .06 & -.08 & .04 & 0 & .16 & .08 \\
\hline
\end{tabular}

\section{Discussions and Conclusions}

In the design of LOs for a chosen learning task, according to the data analysis, the self-perceived novice and experienced ICT users did not significantly differ at using (1) the number of assets (picture, animation, simulation, sound file, hyperlink, game, video, downloadable-file), (2) density of text (small amount, moderate amount and large amount of text), (3) number of instructional elements (advance organizers, questions and didactical directions) and (4) number of screen orientations (sub-topics -Sharable Content Object-, templates, picture orientation, font types and font sizes, colors, main topics) in their LOs. Further, the tests based on subject categories of LOs, the participants' use of assets, instructional elements, and most material organization in the four types of content areas do not significantly differ. The only significant difference is observed at the participants' LOs is at the amount of text; the post hoc tests on four groups' data showed that learning objects for social science units had significantly more text than learning objects for language units. One might think that the social science and language LOs would have similar amount of text due to nature of subject matters, however amount of text in language, science and mathematics LOs seems similar. That may show that pre-servicers authored text in LOs regardless of content area or the use of textual information representation is author dependent rather than content dependent.

The pre-service teachers grouped as self perceived novice and experienced ICT users did not significantly differ on using assets, instructional elements, amount of text and number of screen orientations in developing their LOs. This finding may support the idea of aggregration of content objects in any learning objects is possible and may be achieved by pre-service teachers at different levels of ICT use (Akpinar \& Simsek, 2006); that should encourage the projects not only to ask teachers evaluate and use LOs but also to involve more teachers in developing LO repositories.

The pre-servicers' use of the number of picture orientation on screens of their LOs was similar to number of templates and assets. Use of the number of different font formattings was similar to using the number of topics, maintopics, color, template and instructional elements. The pre- 
servicers' analysis, organisation and use of number of topics was similar to (1) the number of main topics, as expected, (2) number of font formattings and (3) similar to and highly correlated with the use of number of instructional elements and SCOs. Similarly number of instructional elements in their LOs seems to be proportionaly used with SCOs, topics, main topics and font formattings. But the use of instructional elements in their LOs did not significantly correlate with numbers of used assets, templates, picture orientations and colors. This may point that the preservicers tend to organise the LOs on the basis of topical structure of content to be taught.

The reviewers' rating of the LOs developed by the pre-servicers demonstrated that the preservicers are able to develop LOs in "moderate" quality. The LOs are all in "tutorial" mode and most participants sequenced a few SCOs to form a LO. The contents are mostly presented in a didactic manner and student-centered activities are not common in the LOs. Comparisons of ICT novice and ICT experienced pre-servicers' LOs on the basis of reviewers' rating through LORI 1.5 reveal that the groups' LOs did neither differ in overall ratings nor differ at nine individual items of LORI 1.5. The pre-servicers' design of the material type, tutorial, is somewhat different from materials the teachers developed in the study of McCormick et al (2004) where many of designed activities were to reinforce information, however, the LOs of both studies are not learner-centered.

Though not pretty high, there seems to be meaningful relations between the LORI items and the developed LO elements. The significant relationship between presentation design and the number of templates in the LOs is .26 ( $<<.05)$ as minimum, and between content quality and number of topics is $.57(\mathrm{p}<.01)$ as maximum. To a limited degree, the number of main topics used in the developed LOs seems to interact with all of the nine quality issues of the LOs; the number of font formattings has effect on six quality isssues, the number of topics, templates and instructional elements have interaction with five quality issues, the number of SCOs has interaction with three quality issues, text density has effect on simply content quality and number of picture orientation has effect on reusability quality of the LOs. The LORI items have remarkable relations with some of the LO elements, but these results should be used with caution since the results need to be confirmed by different studies and to what extent individual elements of a LO interact with LORI items are not yet clear.

In comparison to previous studies, the findings of this study have similarities to and differences from the previous studies. For example, similar to the findings of Recker and her colleaques' study (2005) that the participants seemed to prefer to use small granularity resources. Thus, participants seemed to be creating simple projects with somewhat directed activities. Recker and her colleaques' explained this result with that the participants were novice users; the current study did not confirm it. Further, Boot (2005) studied novice and experienced designer groups and found out that the groups differed significantly in the average number of information elements and the number of different types of question elements used in their software. According to Boot, the instructional software templates allowed too much freedom to the developers and lacked the needed amount of didactical support, templates restricted the developers' creative freedom. In contrast to Boot's (2005) findings with users in a commercial authoring environments, the groups who used the BU-LeCoMaS did not differ significantly at the average number of information elements and the number of different types of instructional elements used in their LOs; the groups' LO products are not different in quality, too. Further, the provided templates did not entirely restrict the developers' creative freedom, because, in addition to templates, the subjects employed other instructional elements. The different result from Boot's may be due to the fact that the BULeCoMaS did not have as many facilities as commercial authoring systems Boot's study used. It may also be due to level of design experience that the subjects of Boot's study and the current study greatly differed.

This study may agree with Tripp and Bichelmeyer (1990) that instructional software templates 
may positively affect the efficiency of the development process. In this study, the number of templates used in the developed LOs have relatively low but significanlty positive interaction with the qualities of content, learning goal alignment, motivation, presentation design, and standards compliance. Templates may be alternatives, but there is no data in the literature and in this study that templates alone quarantee better quality LOs. Further, the findings also suggest that easy-touse systems may also be designed to support less experienced ICT users' efficient development process. These findings do not show that "when authors use more assests in their LOs or do different number of screen orientation in their LOs, the LO design would definitely be better". But they show that the designed learning content management system is easy for everyone, including novices to design different LOs with or without a template. In other words, one might argue that it is not only the quantity/amount of screen objects in a LO which make LOs interactive, this study is aware of it, but the study aimed to confirm that the content development is managed by even novice ICT users and by teachers' efforts rich LO repositories could be achieved.

The study revealed encouraging results that though it is the first time the subjects of this study developed formal LOs, ICT novice and experienced pre-servicers may develop, at least moderate quality, small and large size learning objects at different content areas. The study concludes that simple design and unexaggerated number of facilities would enable both ICT novice and ICT experienced pre-service teachers in developing learning objects including SCORM compliant type. Quality of LOs are not dependent on the users' self perception of being novice or experienced at ICT, but depends on how the users author LOs under instructional principles in development platforms. The findings and many portal development projects suggest that along with training preservice teachers in ICT, new training modules should be organized to enable them develop interactive LOs which is the subject of further studies.

This research has several limitations including a) classification of ICT users as novice and experienced, b) the lack of follow-up. First, the classification of ICT users as novice and experienced in this study was based upon the respondents' self perception, rather than based on a measurement scale because self-efficacy is based on self-perceptions regarding particular behaviors. ICT users' self-efficacy relates specifically to an individual's judgment of their capabilities to use ICT facilities and is derived from Bandura's (1986) definition of construct of self-efficacy as "peoples judgments of their capabilities to organize and execute courses of action required to attain designated types of performances. It is concerned not with the skills one has, but with the judgements of what one can do with whatever skills one posses" (p.391). Eachus and Cassidy (2006) also confirmed that self-efficacy represents an individual's beliefs regarding their perceived capability to complete a particular behavior or task successfully. An empirical study by Munro, Huff, Marcolin \& Compeau. (1997, p.52) revealed that one's confidence in his/her ability to use a computer is a strong predictor of the person's actual ability. However, further studies may use ICT proficiency tools to classify participants. Second, following the data analysis, little contact occurred with participants to examine the ways they would revise their LOs under the LORI feedback and to inspect their discourse in making decisions of LO components. In addition, actual value of the produced LOs should also be measured with target learners to assure LO quality through observing marked improvements in their learning. Our current work has focused on these issues.

In this work, we have presented the development of a set of facilities that focus on the issues of building virtual environments in a user-friendly and open manner in the Web. To do so we have exploited an object-centred approach of virtual environments and represented them in terms of a set of composed objects. The BU-LeCoMaS targeted here did not replicate all features of commercially available authoring systems; however, it will extend rather than replace capabilities afforded by such systems, and allow additional level of concreteness and modularization for producing a learning objects based environment. 
The framework of supporting students through teachers' collaborative course authoring, considering the different backgrounds of the students and preferred teaching/learning style of teachers/students, should be further evaluated using different task sets in varying subject matter areas. Creation of different type of learning objects in the system and supporting those LOs with learner feedback are now under investigation.

\section{Acknowledgement}

This research was supported by authors' University, Scientific Research Fund under Grant no: 04D201. We thank pre-service teachers who participated in our studies, and appreciate constructive comments provided by anonymous reviewers on the earlier draft of the paper.

\section{References}

Akpinar, Y. (2002). Building in house learning management systems to fulfill organizational requirements. Proceedings of the Third International Conference on Information Technology Based Higher Education and Training. Budapest, Hungary. July 4-6, 89-94.

Akpinar, Y. \& Simsek, H. (2006). Learning object organization behaviors in a home-made learning content management system. Turkish Online Journal of Distance Education, 7(4), Article 3. Retrieved March 19, 2007, from http://tojde.anadolu.edu.tr/tojde24/pdf/article 3.pdf

Bandura, A. (1986). Social foundations of thought and action: A social cognitive theory. Englewood Cliffs, NJ: Prentice Hall.

Barr, M., Holden, S., Phillips, D. \& Greening, T. (1999). An exploration of programming errors in an object-oriented environment. SIGCSE Bulletin, 32(4), 42-46.

Barron, A. (1998). Designing web-based training. British Journal of Educational Technology, 29(4), 355370 .

Barritt, C. \& Alderman, F. L. (2004). Creating a reusable learning objects strategy: Leveraging information and learning in a knowledge economy. San Francisco. Pfeiffer.

Bell, B. (1999). Supporting educational software design with knowledge-rich tools. International Journal of Artificial Intelligence in Education, 10(1), 46-74.

Bennetta, K. \& McGeeb, P. (2005). Transformative power of the learning object debate. Open Learning, 20(1), 15-30.

Boot, E. (2005). Building-block solutions for developing instructional software. Unpublished doctoral dissertation, Open University, The Netherlands. Retrieved March 19, 2007, from http://www.ou.nl/Docs/Expertise/OTEC/Publicaties/Eddybootproefschrift for web0.2.pdf

Boot, E. W. \& Van Rooij, J. C. G. M. (1999). Structured development of computer based training with templates: Analysis. (Report TM-99-A068), TNO Human Factors Research Institute. Soesterberg, The Netherlands.

Boyle, T. (2003). Design principles for authoring dynamic, reusable learning objects. Australian Journal of Educational Technology, 19(1), 46-58.

Cohen, E. B. \& Nycz, M. (2006). Learning objects and e-learning: an informing science perspective. Interdisciplinary Journal of Knowledge and Learning Objects, 2, 23-34. Available at http://ijklo.org/Volume2/v2p023-034Cohen32.pdf

Dunning, J., Rogers, R., Magjuka, R., Waite, D., Kropp, K., Gantz, T., et al. (2004). Technology is too important to leave to technologists. Journal of Asynchronous Learning Networks, 8(3), 11-21.

Eachus, P. \& Cassidy, S. (2006). Development of the web users self-efficacy scale. Journal of Issues in Informing Science \& Information Technology. 3, 199-211. Retrieved March 22, 2007, from http://informingscience.org/proceedings/InSITE2006/IISITEach219.pdf 
Elliott, G. J., Jones, E. \& Barker, P. (2002). A grounded theory approach to modelling learnability of hypermedia authoring tools. Interacting with Computers, 14(5), 547-574.

Friesen, N. (2005) Interoperability and learning objects: An overview of e-learning standardization. Interdisciplinary Journal of Knowledge and Learning Objects, 1, 23-31. Available at http://ijklo.org/Volume1/v1p023-031Friesen.pdf

Garner, K. H. (1990). Twenty rules for arranging text on screen. CBT Directions, 3(5), 13-17.

Grabinger, R. S. (1993). Computer screen designs: Viewer judgments. Educational Technology, Research and Development, 41(2), 35-73.

Hannafin, M. J. \& Hooper, S. (1989). An integrated framework for CBI screen design and layout. Computers in Human Behavior, 5(3), 155-165.

Haughey, M. \& Muirhead, B. (2005). The pedagogical and multimedia designs of learning objects for schools. Australasian Journal of Educational Technology, 21(4), 470-490.

Hazen, M. (1985). Instructional software design principles. Educational Technology, 15(1), 18-23.

Hitzke, C., Fjeld M., Schluep, S. \& Danuser. B. (2002). Learning content production: Acquisition, structuring, representation, and management. Proceedings of 4th International Conference on New Educational Environments, Lugano, Switzerland. May 8-11. 235-240.

IEEE. (2005). LTSC learning object metadata working group. Retrieved March 22, 2007, from http://ieeeltsc.org/wg12LOM

Jones, M. G. (1995). Visuals for information access: A new philosophy for screen and interface design. In Imagery and visual literacy: Selected readings from the annual conference of the International Visual Literacy Association. October 12-16, 1994. Tempe, Arizona. (ERIC Document Reproduction Service No: ED 380 085).

Jones, R. (2004). Designing adaptable learning resources with learning object patterns. Journal of Digital Information, 6(1), Article 305, Retrieved March 22, 2007, from http://jodi.tamu.edu/Articles/v06/i01/Jones/

Kay, R. \& Knaack, L. (2005). Developing learning objects for secondary school students: A multicomponent model. Interdisciplinary Journal of Knowledge and Learning Objects, 1, 229-254. Available at http://www.ijklo.org/Volume1/v1p229-254Kay_Knaack.pdf

Krauss, F. \& Ally, M. (2005). A study of the design and evaluation of a learning object and implications for content development. Interdisciplinary Journal of Knowledge and Learning Objects, 1, 1-22. Available at http://ijklo.org/Volume1/v1p001-022Krauss.pdf

Lajoie, S. P. (2003). Enhancing learning and teaching with emergent technologies. Keynote presentation, ED-MEDIA Conference, June 26. Honolulu, HI. Retrieved March 22, 2007, from http://www.aace.org/conf/edmedia/speakers/lajoie.htm

Li, Z. (2006). Effectively incorporating instructional media into web-based information literacy. The Electronic Library, 24(3), 294-306.

Major, N., Ainsworth, S. \& Wood. D. (1997). REDEEM: Exploiting symbiosis between psychology and authoring environments. International Journal of Artificial Intelligence in Education, 8, 317-340.

McCormick, R., Scrimshaw, P., Li, N. \& Clifford, C. (2004). CELEBRATE Evaluation report (version 2). Retrieved March 22, 2007, from http://celebrate.eun.org/

McGreal, R. (2004) Online education using learning objects. New York: Routledge Falmer.

McNaught, C., Burd, A., Whithear, K., Prescott, J. \& Browning, G. (2003). It takes more than metadata and stories of success: Understanding barriers to reuse of computer facilitated learning resources. Australian Journal of Educational Technology, 19(1), 72-86.

Merriënboer, J. J. G. \& Martens, R. (2002). Computer-based tools for instructional design. Educational Technology, Research and Development, 50, 5-9. 
Milne, I. \& Rowe, G. (2002). Difficulties in learning and teaching programming - Views of students and tutors, Education and Information Technologies, 7(1), 55-66.

Muirhead, B. \& Haughey, M. (2005). An assessment of the learning objects, models and frameworks. Report Developed by The Le@rning Federation Schools Online Curriculum Content Initiative Australia. Retrieved March 22, 2007, from http://www.thelearningfederation.edu.au/tlf2/sitefiles/assets/docs/brochures_reports/research/muirhead haughey 0105.pdf

Munro, M. C., Huff, S. L., Marcolin, B. L., \& Compeau, D. R. (1997). Understanding and measuring user competence. Information \& Management, 33(1), 46-57.

Murray, T., Blessing, S. \& Ainsworth S. (2003). Authoring tools for advanced technology learning environments. Dordrecht, The Netherlands: Kluwer.

Nesbit, J. C. \& Li, J. (2004). Web-based tools for learning object evaluation. Proceedings of the International Conference on Education and Information Systems: Technologies and Applications, Orlando, Florida, USA, 2, 334-339.

Oliver, R., Harper, B., Hedberg, J., Wills, S. \& Agostinho, S. (2002). Formalising the description of learning designs. In A. Goody, J. Herrington \& M. Northcote (Eds.), Quality conversations: Research and development in higher education, 25, 496-504. Jamison, ACT: HERDSA.

Orr, K. L., Golas, K. C. \& Yao, K. (1994). Storyboard development for interactive multimedia training. Journal of Interactive Instruction Development, Winter, 18-31.

Overbaugh, R. C. (1994). Research based guidelines for computer based instruction development. Journal of Research on Computing in Education, 27(1), 29-47.

Porter, D., Curry, J., Muirhead, W. \& Galan, N. (2003). Report on learning object repositories: Review and recommendations for a pan-Canadian approach to repository implementation in Canada. Ottawa: Industry Canada.

Recker, M., Dorward, J., Dawson, D., Mao, X., Liu, Y., Palmer, B., et al. (2005). Teaching, designing, and sharing: A context for learning objects. Interdisciplinary Journal of Knowledge and Learning Objects, 1, 197-216. Available at http://ijklo.org/Volume1/v1p197-216Recker.pdf

Rieber, L. P. (1994). Animation in computer based instruction. Educational Technology, Research and Development, 38(1), 77-86.

SCORM. (2004). Shareable Content Object Reference Model. Retrieved March 22, 2007, from http://www.adlnet.org/scorm/

Shneiderman, B. (2000). Universal usability. Communications of the ACM, 43(5), 84-91.

Sponder, B. \& Hilgenfeld, R. (1994). Cognitive guidelines for teachers developing computer assisted instruction. The Computer Teacher, 22(8), 9-15.

Stemler, L. K. (1997). Educational characteristics of multimedia: A literature review. Journal of Educational Multimedia and Hypermedia, 6(3/4), 339-359.

Taylor, C. D. (1992). Choosing a display format for instructional multimedia: Two screens versus one. Paper presented at convention of the Association for Educational Communications and Technology. (ERIC Document Reproduction Service No. ED 348 019).

Tripp, S. \& Bichelmeyer, B. (1990). Rapid prototyping: An alternative instructional design strategy. Educational Technology, Research and Development, 38, 31-44.

Vargo, J., Nesbit, J.C., Belfer, K. \& Archambault, A. (2003). Learning object evaluation: Computermediated collaboration and inter-rater reliability. International Journal of Computers and Applications, 25(3), 1-8. 
Varlamis, I. \& Apostolakis, I. (2006) The present and future of standards for e-learning technologies. Interdisciplinary Journal of Knowledge and Learning Objects, 2, 59-76. Available at http://www.ijklo.org/Volume2/v2p059-076Varlamis.pdf

\section{Biographies}

Yavuz Akpinar is an associate professor at Boğaziçi University, Department of Computer Education and Educational Technology. His research interests are in interactive learning environments design, human computer interaction, graphical user interfaces, simulations in learning, authoring systems for software design, educational testing, designing and evaluating multimedia and hypermedia in education and training, interactive video, distance education, learning object and e-learning design, Learning managements systems.

Huseyin Simsek is an instructor at Boğaziçi University, Department of Computer Education and Educational Technology. His research interests are in teaching programming and scripting, interactive learning environments design, authoring systems for software design, computer mediated communication, web based learning design, learning managements systems 